\title{
Manejo da biomassa e sustentabilidade nutricional em povoamentos de Eucalyptus spp. em pequenas propriedades rurais
}

\author{
Biomass management and nutritional sustainability of Eucalyptus spp. stands \\ in small farms
}

\author{
Mauro Valdir Schumacher ${ }^{\mathrm{I}}$, Rudi Witschoreck ${ }^{\mathrm{II}}$, Francine Neves Calil ${ }^{\mathrm{III}}$, Vicente Guilherme Lopes ${ }^{\mathrm{IV}}$

\section{Resumo}

O estudo foi realizado com o objetivo de subsidiar práticas de manejo nutricional de povoamentos de Eucalyptus spp. em pequenas propriedades rurais no estado do Rio Grande do Sul. Foram avaliados povoamentos de 2, 4, 6 e 8 anos de idade, com amostragem de 24 árvores e determinação da biomassa e nutrientes nos componentes: folha, galho vivo, galho morto, madeira e casca do tronco e raiz. Também foi estimada a biomassa e o conteúdo de nutrientes no sub-bosque e na serapilheira. A biomassa e o estoque de nutrientes no eucalipto foram estimados por meio do produto dos valores médios por componente, classe diamétrica e número de árvores por hectare, e no sub-bosque e serapilheira, por extrapolação com base na área das unidades amostrais. A eficiência de utilização dos nutrientes no eucalipto foi estimada através do coeficiente de utilização biológico (CUB). Considerando-se o estoque total de nutrientes no eucalipto, em média, a partição, por nutriente, obedeceu a seguinte ordem: Ca (40,0\%), N (25,6\%), K (22,6\%), Mg $(5,9 \%), \mathrm{S}(3,1 \%), \mathrm{P}(2,8 \%)$; e por componente: casca do tronco $(27,5 \%)$, folha $(25,1 \%)$, madeira do tronco $(22,5 \%)$, galho vivo $(14,4 \%)$, raiz $(9,4 \%)$ e galho morto $(1,1 \%)$. A serapilheira e o sub-bosque desempenham importante função na manutenção dos nutrientes no ecossistema florestal, e acumularam em média, em relação ao estoque total no eucalipto, para $\mathrm{N}, \mathrm{P}, \mathrm{K}, \mathrm{Ca}, \mathrm{Mg}$ e S, respectivamente, $47,1 \%, 34,0 \%, 33,6 \%, 32,8 \%, 35,3 \%$ e $36,6 \%$. A colheita florestal realizada em povoamentos jovens acarreta perda no rendimento de madeira do tronco e maior exportação relativa de nutrientes (menor CUB). A colheita total da biomassa de eucalipto acima do solo, quando comparada com a colheita apenas da madeira do tronco, aumentou a exportação de N, P, K, Ca, Mg e S, respectivamente, em 83\%, $152 \%, 193 \%, 445 \%, 305 \%$ e $49 \%$, ao passo que a remoção de biomassa aumentou apenas $20 \%$.

Palavras-chave: Nutrientes; Produtividade florestal; Recursos bioenergéticos

\begin{abstract}
This study was conducted to achieve practical subsidies for nutritional management in Eucalyptus spp. stands in small farms located in Rio Grande do Sul state, Brazil. Different stand ages were evaluated (2, 4, 6 and 8 years old), twenty-four (24) trees were sampled and biomass and nutrients were determined for the following components: leaf, live branch, dead branch, wood and bark from the trunk and root. Biomass and nutrient content in the understory and litter were also estimated. Biomass and nutrients stock in eucalypts were estimated through the product of the mean values for each component, diametric class and number of trees per hectare, and in understory and litter, it was obtained through extrapolation based on the sample unit areas. Utilization efficiency from eucalyptus nutrients was estimated through the coefficient of biological utilization (CUB). Considering total nutrients stock in the eucalyptus, nutrients partition followed this order: $\mathrm{Ca}(40.0 \%), \mathrm{N}(25.6 \%), \mathrm{K}(22.6 \%), \mathrm{Mg}(5.9 \%), \mathrm{S}(3.1 \%), \mathrm{P}(2.8 \%)$; and for component: trunk bark (27.5\%), leaf (25.1\%), wood trunk $(22.5 \%)$, live branch $(14.4 \%)$, root $(9.4 \%)$ and dead branch $(1.1 \%)$. Litter and understory play an important role in nutrients maintenance in forest ecosystems and accumulate (in average), based on the total stock for eucalyptus, for $\mathrm{N}, \mathrm{P}, \mathrm{K}, \mathrm{Ca}, \mathrm{Mg}$ and $\mathrm{S}$, respectively, 47.1\%, 34.0\%, $33.6 \%, 32.8 \%, 35.3 \%$ and $36.6 \%$. Forest harvesting in young stands leads to loss in wood yield and a higher nutrients relative export (lower CUB). The total eucalyptus biomass harvest above the soil, when compared to the harvest of only the trunk wood, increased the exports of N, P, K, Ca, Mg and S, respectively, in 83\%, 152\%, 193\%, respectively. $445 \%, 305 \%$ and $49 \%$, while the removal of biomass increased only $20 \%$.
\end{abstract}

Keywords: Nutrients; Forest productivity; Bioenergetics resources

\footnotetext{
I Engenheiro Florestal, Dr., Professor do Departamento de Ciências Florestais, Centro de Ciências Rurais, Universidade Federal de Santa Maria, Av. Roraima, 1000, CEP 97105-900, Santa Maria (RS), Brasil. schumacher@pesquisador.cnpq.br (ORCID: 0000-0003-3277-5671)

II Engenheiro Florestal, Dr., Laboratório de Ecologia Florestal, Centro de Ciências Rurais, Universidade Federal de Santa Maria, Av. Roraima, 1000, CEP 97105-900, Santa Maria (RS), Brasil. rwitschoreck@yahoo.com.br (ORCID: 0000-0003-3274-0815)

${ }^{\text {III }}$ Engenheira Florestal, Dra., Professora da Escola de Agronomia da Universidade Federal de Goiás, Av. Esperança, s/n. Campus Samambaia, CEP 74.690-900, Goiânia (GO), Brasil. fncalil@gmail.com (ORCID: 0000-0003-2882-9622)

${ }^{\text {IV }}$ Engenheiro Florestal, Dr., Professor do Curso de Engenharia Ambiental e Sanitária, Universidade Federal do Pampa, Av. Pedro Anunciação, 111, CEP 96570-000, Caçapava do Sul (RS), Brasil. vicentelopes@unipampa.edu.br (ORCID: 0000-0002-0324-994X)
} 


\section{Introdução}

O eucalipto é a essência mais utilizada em plantios florestais no Brasil, em 2015, dos 7,8 milhões de hectares de área total, 5,6 milhões de hectares ou 71,8\% eram ocupados com espécies desse gênero, dos quais, $6 \%$ pertenciam ao Rio Grande do Sul (INDÚSTRIA BRASILEIRA DE ÁRVORES, 2016).

O desenvolvimento rural sustentável implica no planejamento adequado do processo de produção agrícola e florestal, identificando e protegendo adequadamente as áreas de proteção para que se preserve água, biodiversidade e outros serviços ambientais, de forma a possibilitar o uso racional dos espaços produtivos da paisagem. No caso de plantações florestais, por exemplo, o setor evoluiu bastante neste sentido, com a adoção de práticas sustentáveis de manejo florestal.

$\mathrm{Na}$ área do presente estudo, os plantios de eucalipto apresentam vários aspectos positivos. Economicamente, as florestas proporcionam biomassa barata que viabiliza atividades que necessitam dessa fonte de energia. Ecologicamente, além de amenizar a pressão sobre os parcos remanescentes de florestas naturais, os plantios de eucalipto possibilitam a melhor utilização da área das propriedades, permitindo a reintegração de áreas marginais, mal drenadas ou de topografia mais acidentada, nas quais desempenham importante papel na preservação do solo e dos recursos hídricos.

Mais recentemente, as florestas de crescimento rápido, principalmente, como as de eucalipto, estão sendo indicadas como possíveis drenos do carbono atmosférico. Desde a revolução industrial, em decorrência da utilização de combustíveis fósseis e da destruição das florestas naturais, houve uma elevação de mais de $20 \%$ na concentração de dióxido de carbono $\left(\mathrm{CO}_{2}\right)$ na atmosfera (LAL; KIMBLE; FOLLETT, 1998). O efeito estufa é natural e necessário para a continuidade da vida na Terra, porém, a intensificação desse fenômeno, causada por atividades humanas, está causando a mudança climática global (GUREVITCH; SCHEINER; FOX, 2009). Como os vegetais têm a capacidade de fixar o carbono, os plantios de floresta têm se mostrado uma alternativa para o "sequestro de carbono".

Os povoamentos florestais são sistemas abertos sujeitos a um grande número de entradas e saídas de elementos químicos, muitos deles reconhecidos como nutrientes essenciais ao desenvolvimento vegetal (EPSTEIN; BLOOM, 2006; PALLARDY, 2008). O entendimento da ciclagem de nutrientes nos ecossistemas florestais é um pré-requisito essencial para a compreensão e a predição dos efeitos da nutrição no crescimento da floresta (LANDSBERG, 1986); e um dos aspectos fundamentais para a manutenção da produtividade florestal (REIS; BARROS, 1990). As entradas de nutrientes no sistema podem ocorrer através das deposições atmosféricas (secas e úmidas), intemperismo geológico, fixação biológica de nitrogênio e fertilização, enquanto que as saídas incluem a volatilização pelas queimadas ou pela desnitrificação, a lixiviação e a erosão hídrica, assim como a colheita da biomassa (PRITCHETT, 1990). Normalmente, a colheita florestal é a principal via de exportação de nutrientes dos sítios florestais, sobretudo se realizada em rotações curtas e envolvendo outros componentes da biomassa, além da madeira.

Este trabalho teve como objetivo caracterizar a produção de biomassa e a distribuição e eficiência de utilização dos nutrientes ao longo do ciclo produtivo dos povoamentos de Eucalyptus spp., em pequenas propriedades rurais, para orientar o manejo adequado da biomassa com vistas à sustentabilidade nutricional.

\section{Material e método}

Localização e caracterização da área do estudo

O estudo foi realizado em pequenas propriedades rurais no município de Vera Cruz, no estado do Rio Grande do Sul, em povoamentos de 2, 4, 6 e 8 anos de idade, nas seguintes coordenadas geográficas: $29^{\circ} 44^{\prime} 55,2^{\prime \prime}$ S e $52^{\circ} 29^{\prime} 50,2^{\prime \prime}$ W; $29^{\circ} 47^{\prime} 42,2^{\prime \prime}$ S e $52^{\circ} 31^{\prime} 57,5^{\prime \prime}$ W; $29^{\circ} 44^{\prime} 48,8^{\prime \prime}$ S e $52^{\circ} 29^{\prime} 41,8^{\prime \prime}$ W e $29^{\circ}$ 47’36,0" S e 52³1'57,5” W, respectivamente. Segundo Köppen, a área compreende o tipo climático Cfa2, que corresponde ao clima subtropical (MORENO, 1961). A precipitação pluviométrica da região fica em torno de $1.650 \mathrm{~mm}$ anuais. Os solos pertencem ao Grupo São Bento, tendo com material de origem arenitos, siltitos e argilitos da Formação Rosário do Sul (Santa Maria), originados de deposições sedimentares 
de natureza flúvio-lacustre do período Triássico (VIEIRA, 1984). A Tabela 1 apresenta algumas características químicas do solo dos povoamentos estudados, em que se destaca uma condição de elevada acidez e baixo nível de fertilidade.

Tabela 1 - Caracterização do solo da área do estudo, na profundidade de 0 - $20 \mathrm{~cm}$.

Table 1 - Soil characterization in the studied area, in depth from 0 to $20 \mathrm{~cm}$.

\begin{tabular}{|c|c|c|c|c|c|c|c|c|c|c|c|}
\hline \multirow{2}{*}{$\begin{array}{l}\text { Povoamento } \\
\text { (idade) }\end{array}$} & \multirow{2}{*}{$\frac{\text { M.O. }}{\text { (\%) }}$} & \multirow{2}{*}{$\underset{\text { (água) }}{\mathrm{pH}}$} & $\mathbf{P}$ & $\mathbf{K}$ & $\mathrm{Ca}$ & $\mathbf{M g}$ & Al & CTC $_{\text {efe }}$ & $\mathrm{CTC}_{\mathrm{pH}} 7$ & $\mathbf{v}$ & $\mathbf{m}$ \\
\hline & & & & & \multicolumn{5}{|c|}{$\mathrm{cmol}_{\mathbf{c}} \mathbf{d m}^{-3}$} & \multicolumn{2}{|c|}{$(\%)$} \\
\hline 2 anos & 1,5 & 4,4 & 1,1 & 21,7 & 1,4 & 0,4 & 2,5 & 4,3 & 8,3 & 23,3 & 58,8 \\
\hline 4 anos & 1,0 & 4,2 & 2,4 & 16,0 & 0,5 & 0,2 & 1,0 & 1,7 & 4,8 & 19,7 & 56,8 \\
\hline 6 anos & 1,5 & 4,8 & 12,9 & 32,0 & 2,2 & 1,1 & 0,7 & 4,1 & 7,4 & 45,5 & 17,5 \\
\hline 8 anos & 1,5 & 4,3 & 14,2 & 25,0 & 0,7 & 0,3 & 1,0 & 2,0 & 5,0 & 21,2 & 48,7 \\
\hline
\end{tabular}

Em que: $\mathrm{P}$ e K: extração com solução Mehlich-1; Ca, Mg e Al: extraídos por solução de $\mathrm{KCl}(1$ mol L-1); M.O.: digestão por combustão úmida $\left(\mathrm{K}_{2} \mathrm{Cr}_{2} \mathrm{O}_{7}+\mathrm{H}_{2} \mathrm{SO}_{4}\right)$.

\section{Amostragem de biomassa}

Os povoamentos foram selecionados de modo que representassem as condições de cultivo da espécie florestal em área de primeiro corte na região do estudo. O inventário florestal consistiu na distribuição aleatória de quatro parcelas de $12 \mathrm{~m}$ x $20 \mathrm{~m}$, em cada um dos povoamentos, foram medidos todos os diâmetros das árvores a altura do peito (dap), com auxílio de uma fita diamétrica, e $20 \%$ da altura total das árvores mais altas, com hipsômetro de precisão.

A partir dos dados obtidos no inventário florestal, a amplitude diamétrica observada em cada povoamento foi dividida em 3 classes de diâmetro (dap), sendo abatidas duas árvores com diâmetro médio em cada classe, totalizando 6 árvores por povoamento. Após o abate de cada árvore-amostra, a biomassa foi dividida em folha, galho vivo, galho morto, madeira, casca e raiz. Paralelamente à determinação de biomassa foi realizada uma cubagem rigorosa do fuste, segundo o método de Smalian. Para facilitar a pesagem e a obtenção das medidas de diâmetro, com e sem casca, o tronco foi secionado nos pontos de cubagem $(0,1 ; 0,3 ; 1,3 ; 2,3 ; 3,3 \mathrm{~m}$; e assim, sucessivamente, a intervalos de 1 metro, até o diâmetro mínimo de $3 \mathrm{~cm}$ (a partir do qual, foi considerado como galho vivo). Cada secção do tronco foi pesada com e sem casca para definir a biomassa de madeira e casca. A biomassa de raiz foi determinada após escavação do sistema radicular, manual e com retroescavadeira, até que se observassem raízes. Antes da pesagem as raízes foram lavadas para a retirada do solo aderido.

Neste estudo foi considerado como sub-bosque todo tipo de vegetação, de ocorrência espontânea, seja nativa ou exótica. No centro de cada uma das parcelas do inventário florestal foi demarcada uma parcela de $4 \mathrm{~m} \times 3 \mathrm{~m}$, na qual foi coletada toda a biomassa acima e abaixo do solo (raízes), pesada e amostrada. Em cada uma das parcelas, foram coletadas 10 amostras de serapilheira de $25 \mathrm{~cm} \times 25 \mathrm{~cm}$, totalizando 40 amostras por povoamento. As amostras coletadas foram pesadas em balança digital, identificadas e armazenadas em saco de papel.

\section{Estimativa de biomassa e nutrientes}

Para determinação do teor de umidade e a concentração de nutrientes em cada árvore-amostra foi coletada uma amostra de folha, galho vivo, galho morto e raiz, e 3 amostras de casca e madeira, nas seguintes posições ao longo do fuste: dap, a $50 \%$ e a $75 \%$ da altura total da árvore. No laboratório, as amostras foram secas a $70^{\circ} \mathrm{C}$, em estufa com circulação e renovação de ar, até estabilização do peso. Após a secagem, as amostras foram pesadas novamente para determinação da massa seca. As amostras foram 
moídas em moinho de lâminas do tipo Wiley com peneira de 20 mesh. As determinações analíticas de N, P, $\mathrm{K}, \mathrm{Ca}, \mathrm{Mg}$ e S, foram realizadas segundo a metodologia sugerida por Miyazawa et al. (1999). O nitrogênio foi determinado pelo método Kjeldhal, no extrato de digestão sulfúrica, e os demais elementos, no extrato de digestão nítrico-perclórica, sendo cálcio e magnésio por espectrofotometria de absorção atômica, fósforo por espectrofotometria (VIS), potássio por fotometria de chama e enxofre por turbidimetria.

A análise estatística ficou restrita à estatística descritiva, com medidas de posição e dispersão. A estimativa da biomassa de eucalipto por hectare foi obtida do produto entre a biomassa média de cada componente e o número de árvores por hectare por classe diamétrica, em cada povoamento. No caso do sub-bosque e serapilheira, o cálculo foi realizado com base na biomassa média em função da área amostral. O estoque de nutrientes nos diferentes compartimentos da vegetação (eucalipto, sub-bosque e serapilheira) foi determinado pelo produto entre biomassa e a concentração de nutrientes.

A fim de avaliar a taxa de conversão de nutrientes em biomassa ao longo do desenvolvimento dos povoamentos, e consequentemente, a exportação relativa de nutrientes por unidade de biomassa, foi estimado o coeficiente de utilização biológico (CUB), obtido pelo quociente entre a biomassa e o estoque de nutriente, ambos com a mesma unidade, como indicado na fórmula abaixo (BARROS et al., 1986).

\section{Resultados e discussão}

Características dendrométricas dos povoamentos

Apesar de grande variabilidade no espaçamento, de modo geral, os povoamentos são implantados sob excessiva densidade populacional, na sua maioria, em torno de $3 \mathrm{~m}^{2}$ por planta, mas que devido à taxa de mortalidade, apresentam redução no número de indivíduos algum tempo após o plantio (Tabela 2). Apesar disso, os índices de produtividade, em termos de volume de madeira com casca, são elevados, evidenciando o grande potencial produtivo dos solos da região para a silvicultura. Os povoamentos estudados não receberam qualquer tipo de fertilização por ocasião do plantio, no entanto, em virtude da proximidade de cultivos agrícolas, notadamente o fumo, que recebe uma carga elevada de fertilizantes, pode ter havido algum aporte via escorrimento superficial.

Tabela 2 - Características dendrométricas dos povoamentos de Eucalyptus spp. em pequenas propriedades rurais, Vera Cruz - RS.

Table 2 - Dendrometric characteristics from Eucalyptus spp. stands in small farms, Vera Cruz, RS state.

\begin{tabular}{lcccc}
\hline \multicolumn{1}{c}{ Parâmetro } & \multicolumn{3}{c}{ Idade do povoamento (anos) } \\
\cline { 2 - 5 } & $\mathbf{2}$ & $\mathbf{4}$ & $\mathbf{6}$ & $\mathbf{8}$ \\
\hline Dap (cm) & 6,5 & 6,8 & 12,8 & 13,2 \\
Densidade (árvores ha $\left.{ }^{-1}\right)$ & 2645,8 & 3569,4 & 2354,2 & 2375 \\
Altura dominante $(\mathrm{m})$ & 11,9 & 14,0 & 27,4 & 28,6 \\
Volume de madeira com casca $\left(\mathrm{m}^{3} \mathrm{ha}^{-1}\right)$ & 48,4 & 80,2 & 344,4 & 414,0 \\
Volume de madeira sem casca $\left(\mathrm{m}^{3} \mathrm{ha}^{-1}\right)$ & 36,5 & 62,9 & 307,2 & 370,6 \\
\hline
\end{tabular}

Em que: Dap = diâmetro à altura do peito.

\section{Produção de biomassa e estoque de nutrientes}

Apesar do aumento absoluto nos valores de biomassa em função da idade (Figura 1, A), a produção relativa de folha, galho vivo, galho morto, casca e raiz diminuiu, ao passo que a madeira do tronco aumentou (Figura 1, B). Devido à desrama natural, galhos mortos não foram encontrados nos povoamentos 
de 6 e 8 anos. A observação dos valores relativos de biomassa de madeira do tronco (Figura 1, B) permite concluir que colheitas precoces, antes dos 6 anos de idade, acarretam perda no rendimento de madeira.

A partição de biomassa sofre forte controle genético, entretanto, pode variar nas diferentes fases de crescimento das árvores, além da influência das condições de desenvolvimento, como a densidade de plantio. Leite et al. (1997) estudando Eucalyptus grandis em Santa Barbara - MG e Ladeira et al. (2001) na região de Três Marias - MG em povoamentos de Eucalyptus camaldulensis, Eucalyptus pellita e Eucalyptus urophylla, constataram, sob diferentes espaçamentos de plantio, que a medida que a densidade de plantas aumenta a produção por unidade de área também aumenta, ao passo que a biomassa por planta diminui. Esses autores também verificaram que quanto menor o espaçamento entre plantas maior a alocação de biomassa no tronco e menor na copa. Além do espaçamento em si, o arranjo espacial das plantas na linha e na entrelinha de plantio pode influenciar a produção de biomassa, quando considerada a mesma densidade populacional, como ficou demonstrado por Assis et al. (1999) para Eucalyptus urophylla na região de cerrado de Minas Gerais.

Em relação à idade dos povoamentos, Ladeira et al. (2001) observaram entre 15 e 84 meses pósplantio que a biomassa relativa de madeira e casca do tronco aumentou em função da idade, enquanto o inverso aconteceu com galho e folha.

\section{Figura 1 - Distribuição absoluta (A) e relativa (B) da biomassa de Eucalyptus spp. em plantios de diferentes idades em pequenas propriedades rurais, Vera Cruz - RS.}

Figure 1 - Absolute (A) and relative (R) Eucalyptus spp. biomass distribution in different age plantations in small farms, Vera Cruz, RS state.

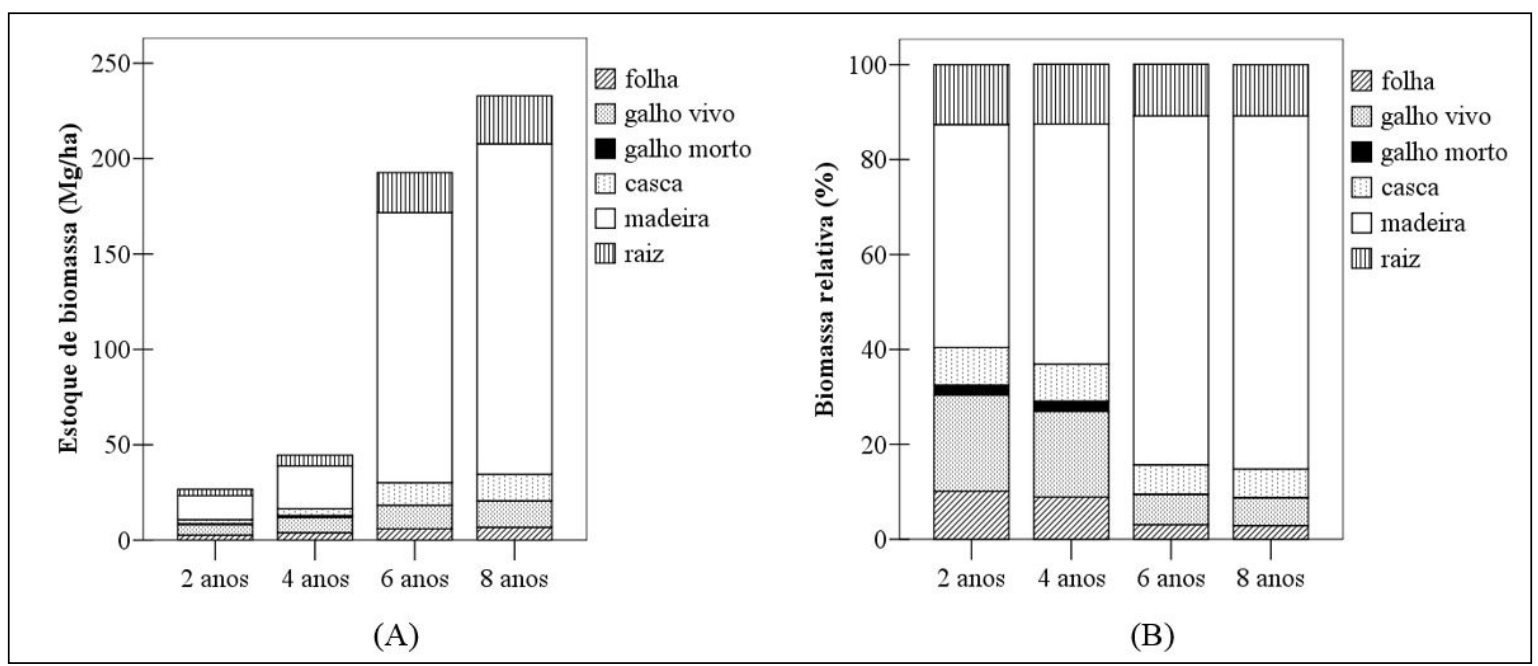

Na Figura 2 apresenta-se o conteúdo de nutrientes nos componentes da biomassa de eucalipto, no qual é possível observar que o acúmulo médio, considerando os quatro povoamentos, obedece a seguinte ordem decrescente: $\mathrm{Ca}(40 \%), \mathrm{N}(25,6 \%), \mathrm{K}(22,6 \%), \mathrm{Mg}(5,9 \%), \mathrm{S}(3,1 \%), \mathrm{P}(2,8 \%)$; e para os componentes da biomassa: casca do tronco $(27,5 \%)$, folha $(25,1 \%)$, madeira do tronco $(22,5 \%)$, galho vivo $(14,4 \%)$, raízes $(9,4 \%)$ e galho morto $(1,1 \%)$.

O acúmulo de nutrientes em valores absolutos na casca foi grande, considerando-se a pequena biomassa relativa desse componente. Em média, a casca representou $7 \%$ da biomassa total de eucalipto, no entanto, foi o principal componente em acúmulo de nutrientes, principalmente, devido ao elevado conteúdo de $\mathrm{Ca}$, que representa $69,7 \%$ do seu conteúdo nutricional. A casca do tronco foi o principal componente em acúmulo de $\mathrm{Ca}(47,6 \%), \mathrm{P}(30,3 \%)$ e $\mathrm{Mg}(29,1 \%)$.

A despeito da pequena biomassa relativa, o componente folha foi o segundo em acúmulo de nutrientes. Com uma biomassa relativa média de apenas $6,2 \%(10,1 \%, 8,9 \%, 3,1 \%$ e $2,9 \%$, respectivamente, aos 2, 4, 6 e 8 anos de idade), o componente folha foi o principal em conteúdo de $\mathrm{N}(40,6 \%)$ e $\mathrm{K}(29,0 \%)$, e o segundo em P $(26,2 \%)$, $M g(28,2 \%)$ e S $(25,9 \%)$. 
Em contraste com os demais componentes, a madeira do tronco se destaca, principalmente, pelo predomínio na alocação de biomassa. Em média, com mais de $60 \%$ da biomassa total, apresentou tendência crescente no acúmulo de biomassa em função da idade do povoamento (Figura 1), passando de 47,0\% aos dois anos de idade, para $74,4 \%$ aos 8 anos. Apesar da elevada alocação de biomassa, a madeira do tronco é somente o terceiro componente em estoque de nutrientes, sendo o primeiro em acúmulo de $\mathrm{S}(41,9 \%)$, e o segundo em N $(31,6 \%)$ e $\mathrm{K}(26,1 \%)$.

Figura 2 - Estoque de nutrientes nos diferentes componentes da biomassa em plantios de Eucalyptus spp. com diferentes idades em pequenas propriedades rurais, Vera Cruz - RS.

Figure 2 - Nutrients stock in different biomass components in different ages Eucalyptus spp. plantations in small farms, Vera Cruz, RS state.

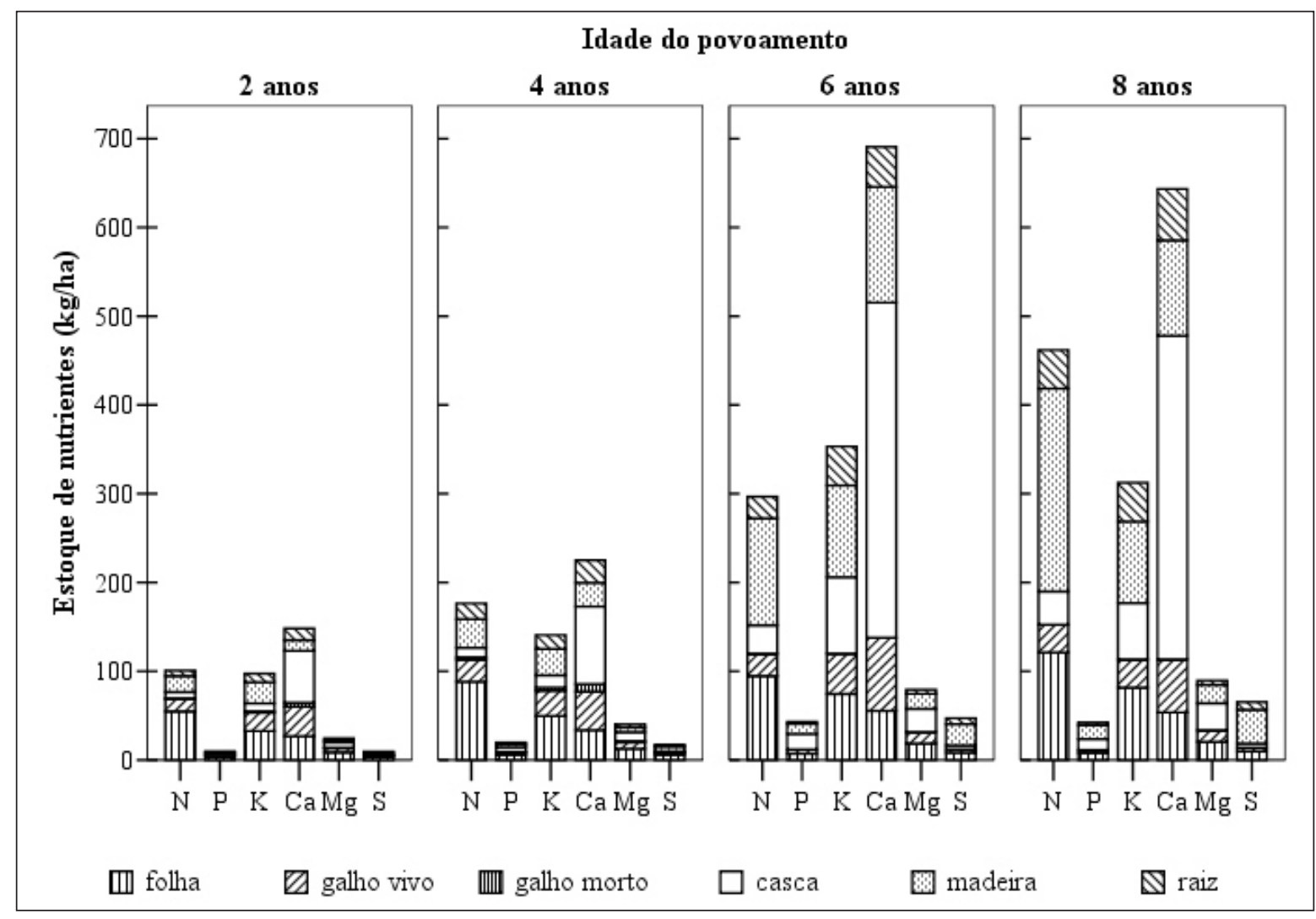

Galhos vivos e raiz representaram uma condição intermediária, em relação aos outros componentes, com valores médios para a partição de biomassa e nutrientes, respectivamente, em torno de 13 e $14 \%$ e 12 e $9 \%$, do total no eucalipto.

Galhos mortos apresentaram valores de acúmulo de nutrientes proporcionais à alocação de biomassa, que foi aproximadamente $2 \%$, considerando-se somente os povoamentos de 2 e 4 anos de idade.

Como foi observado, o estoque de nutrientes nos diferentes componentes das árvores, em regra, não acompanha a distribuição de biomassa devido à diferença na concentração de nutrientes. Segundo Bellote e Silva (2004), a concentração de nutrientes nos componentes da biomassa está relacionada com suas funções, apresentando, geralmente, o seguinte gradiente: folha $>$ casca $>$ ramo $>$ tronco (alburno $>$ cerne). A folha é o grande centro metabólico da planta, o que fica evidente pelo predomínio dos teores mais elevados de nutrientes (MARSCHNER, 1995). Por outro lado, os teores mais baixos estão associados a componentes que têm função mais estrutural ou de condução, como é o caso da madeira e dos galhos (BINKLEY, 1986).

Em todas as idades, o eucalipto se destaca em alocação de biomassa e conteúdo nutricional, no entanto, é evidente a importância dos demais compartimentos na partição de nutrientes, sobretudo 
da serapilheira (Figura 3). O estoque de biomassa nos povoamentos de 2, 4, 6 e 8 anos de idade, respectivamente, foi de 4,05; 5,98; 11,80 e 12,28 $\mathrm{Mg} \mathrm{ha}^{-1}$ na serapilheira e 1,87; 1,97; 4,37 e 8,24 Mg ha-1 no sub-bosque, ante 26,70; 44,55; 192,67 e $233,93 \mathrm{Mg} \mathrm{ha}^{-1}$ no eucalipto. Pereira et al. (1984) estudando Eucalyptus grandis em uma sequência de idades encontraram 1,$10 ; 2,40 ; 4,25 ; 5,66 ; 6,60 ; 7,70$ e 11,80 Mg $\mathrm{ha}^{-1}$ de serapilheira acumulada, respectivamente, aos 1, 2, 3, 4, 5, 6 e 7 anos de idade.

Em razão da maior concentração de nutrientes, sobretudo no sub-bosque, o conteúdo nutricional é mais expressivo que o estoque de biomassa. Em média, considerando-se os quatro povoamentos, o estoque de N, P, K, Ca, Mg e S, em kg ha ${ }^{-1}$, respectivamente, foi de 49,6;5,4; 44,7; 22,8; 5,8 e 5,7 no sub-bosque, 72,$5 ; 4,3 ; 31,2 ; 117,3 ; 14,8$ e 7,0 na serapilheira e 258,$9 ; 28,7 ; 225,8 ; 426,8 ; 58,4$ e 34,7 no eucalipto. Se considerados ambos os compartimentos, serapilheira e sub-bosque, esses armazenam uma quantidade de $\mathrm{N}, \mathrm{P}, \mathrm{K}, \mathrm{Ca}, \mathrm{Mg}$ e S, respectivamente, equivalente a 47,1\%;34,0\%; 33,6\%;32,8\%; 35,3\% e $36,6 \%$ do estoque no eucalipto; o que indica a magnitude do impacto nutricional advindo da remoção desses compartimentos do sistema.

Figura 3 - Estoque de nutrientes e biomassa nos compartimentos eucalipto, sub-bosque e serapilheira, dos plantios de Eucalyptus spp. com diferentes idades em pequenas propriedades rurais, Vera Cruz - RS.

Figure 3 - Biomass and nutrients stock in eucalyptus compartments, understory and litter, in different Eucalyptus spp. plantation ages in small farms, Vera Cruz, RS state.

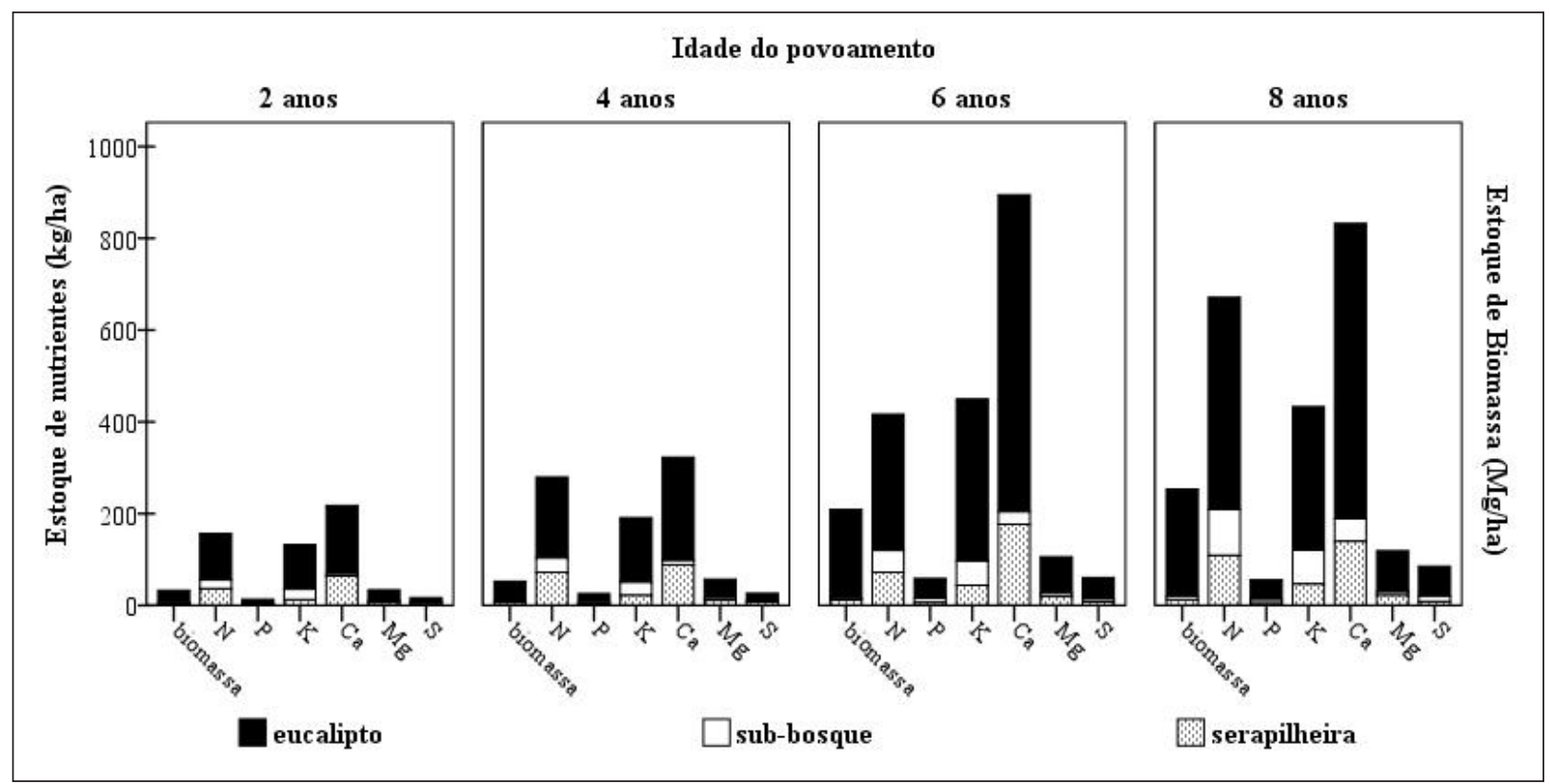

Waring e Schlesinger (1985) afirmaram que devido à alta concentração de nutrientes e à elevada proporção da folhagem, o sub-bosque tem mais importância na ciclagem de nutrientes do que a sua pequena biomassa pode indicar. Do mesmo modo, Costa (1990) salientou a importância da heterogeneidade da comunidade vegetal de plantios florestais, como forma de manutenção dos nutrientes no sistema soloplanta. Em função das diferentes exigências nutricionais, quanto maior a heterogeneidade da comunidade vegetal, melhor será o equilíbrio dos nutrientes no ecossistema.

Além disso, o sub-bosque apresenta aspectos conservacionistas muito importantes, sobretudo em áreas de topografia acidentada, juntamente com as árvores de eucalipto e a serapilheira, funciona como uma barreira física ao escoamento superficial protegendo o solo contra a erosão. A comunidade vegetal também é eficiente na remoção do excesso de nutrientes dissolvidos na água, como nitratos e sulfatos, e é capaz de reter partículas finas de solo que transportam outros nutrientes, menos solúveis, como fósforo e cálcio; evitando a saída dos nutrientes do sistema causando poluição em lagos e cursos d'água (TROEH; THOMPSON, 2007). 
Como a decomposição da matéria orgânica, além das características externas (edafoclimáticas), depende da própria constituição do material, o sub-bosque pode atuar de forma positiva na ciclagem de nutrientes: enriquecendo a serapilheira, favorecendo a fixação de nitrogênio, aumentando as taxas de decomposição e disponibilização de nutrientes através da criação de um microclima mais propício para os processos metabólicos de decomposição. Portanto, se na fase inicial, as plantas invasoras podem restringir o desenvolvimento da floresta, devido à competição por água, luz e nutrientes, nas fases subsequentes, a presença de sub-bosque pode ter mais reflexos positivos do que negativos, potencializando os efeitos benéficos da cobertura vegetal na preservação do solo.

O retorno de nutrientes via deposição de serapilheira representa a via mais importante do ciclo biogeoquímico, principalmente em áreas com solos altamente intemperizados, em que a biomassa representa o principal estoque de nutrientes (REIS; BARROS, 1990). Após o fechamento das copas, ocorre redução na absorção de nutrientes e da dependência de fontes externas (p. ex. fertilização) e boa parte da demanda de nutrientes provém da deposição de serapilheira (ciclagem biogeoquímica) e da retranslocação interna (ciclagem bioquímica) (GONÇALVES et al., 2004). A retranslocação dos nutrientes de tecidos em senescência para regiões da planta com maior atividade metabólica é uma importante estratégia para aumentar a eficiência de utilização dos nutrientes com alta mobilidade no tecido vegetal, e reduzir as saídas no processo de deposição de serapilheira (POGGIANI; SCHUMACHER, 2004).

Ao estudar povoamentos de Eucalyptus saligna, Gonçalves et al. (1997) apud Gonçalves et al. (2004), puderam constatar uma retranslocação média de nutrientes, das folhas decíduas para outros drenos das árvores, entre o oitavo e o nono ano de idade, da seguinte ordem: $79 \%$ do N, $67 \%$ do P, $81 \%$ do K, $51 \%$ do $\mathrm{Mg}, 18 \%$ do B, $79 \%$ do $\mathrm{Zn}, 37 \%$ do $\mathrm{Cu}, 28 \%$ do Fe e $14 \%$ do Mn, e para os galhos decíduos: $67 \%$ do N, $66 \%$ do P, $87 \%$ do $\mathrm{K}, 48 \%$ do $\mathrm{Mg}, 38 \%$ do B, $66 \%$ do $\mathrm{Zn}, 17 \%$ do $\mathrm{Cu}, 30 \%$ do Fe e $52 \%$ do Mn. A partir disso, depreende-se que, em povoamentos adultos, grande parte da demanda anual de nutrientes é suprida pela ciclagem de nutrientes e em função disso, a resposta à adubação diminui com a idade pós-plantio.

Nas condições deste estudo, do ponto de vista da sustentabilidade nutricional, tanto a serapilheira como o sub-bosque devem ser vistos como compartimentos de transição para os nutrientes. Um estoque, que após decomposição, pode liberar quantidades expressivas de nutrientes, tanto no ciclo atual como nos subsequentes.

\section{Impacto nutricional da colheita da biomassa}

A magnitude da exportação de nutrientes é diretamente proporcional à quantidade de biomassa e ao teor nutricional dos componentes envolvidos na colheita florestal. O teor de nutrientes varia em função de fatores como: espécie (capacidade de absorção, distribuição e utilização dos nutrientes); época do ano, componente da biomassa; solo (fertilidade); idade da floresta e condições de desenvolvimento (densidade de plantio, competição) (BINKLEY, 1986; REIS; BARROS, 1990; PALLARDY, 2008). Uma forma de expressar conjuntamente os diversos fatores que condicionam a concentração de nutrientes no tecido vegetal é o CUB (BARROS et al., 1986). O CUB representa quantas unidades de biomassa são formadas por unidade de nutriente, ou seja, quanto maior o valor, mais eficiente é a conversão dos nutrientes em biomassa. Em termos práticos, esse coeficiente deve ser o maior possível, com isso, será exportado menos nutriente por unidade de biomassa.

Na Figura 4 apresenta-se o CUB, calculado com base na biomassa total de eucalipto, no qual se verifica grande variação entre os nutrientes e a seguinte ordem de eficiência de utilização de nutrientes no povoamento com 8 anos: $\mathrm{P}>\mathrm{S}>\mathrm{Mg}>\mathrm{K}>\mathrm{N}>\mathrm{Ca}$ (Figura 4). $\mathrm{O}$ padrão para os nutrientes, em relação à idade, apresentou variações, possivelmente, em razão da heterogeneidade, especialmente, do material genético e das condições de solo. Não obstante, resguardando-se as condições desiguais entre os povoamentos, é possível constatar uma tendência crescente dos valores do CUB em função da idade, o que sugere uma maior exportação relativa de nutrientes nas colheitas realizadas em povoamentos jovens.

$\mathrm{O}$ estoque de nutrientes na biomassa florestal tende a apresentar um comportamento assintótico em idades avançadas, alcançando um estado de equilíbrio, cujo incremento através do crescimento das árvores é contrabalançado com a morte de indivíduos (WARING; SCHLESINGER, 1985) e pela ciclagem de nutrientes. A ciclagem interna (ciclagem bioquímica) desloca nutrientes de tecidos senescentes para 
regiões com maior atividade metabólica (REIS; BARROS, 1990; PALLARDY, 2008), o que é especialmente importante nos tecidos lenhosos, na transformação de alburno em cerne. Segundo Burger e Richter (1991), o alburno, localizado nas camadas mais periféricas do tronco, constitui-se em tecido mais ativo fisiologicamente que o cerne (parte central do tronco) e diferentemente deste, é constituído por células parenquimáticas vivas que encerram substâncias nutritivas como amido, açúcares, proteínas, entre outros; o que lhe confere maior concentração de nutrientes. A manutenção de células não fotossintetizantes no tronco, galhos e raízes em árvores adultas representa uma grande demanda por carboidratos. À medida que as árvores crescem o volume total de alburno também aumenta, mas o percentual na secção transversal do tronco diminui (WARING; SCHLESINGER, 1985), o que eleva a eficiência de utilização dos nutrientes (maior CUB).

\section{Figura 4 - Coeficiente de utilização biológica de nutrientes para a biomassa total em plantios de diferentes idades de Eucalyptus spp. em pequenas propriedades rurais, Vera Cruz - RS.}

Figure 4 - Nutrient biological utilization coefficient for total biomass in different Eucalyptus spp. ages plantations in small farms, Vera Cruz, RS state.

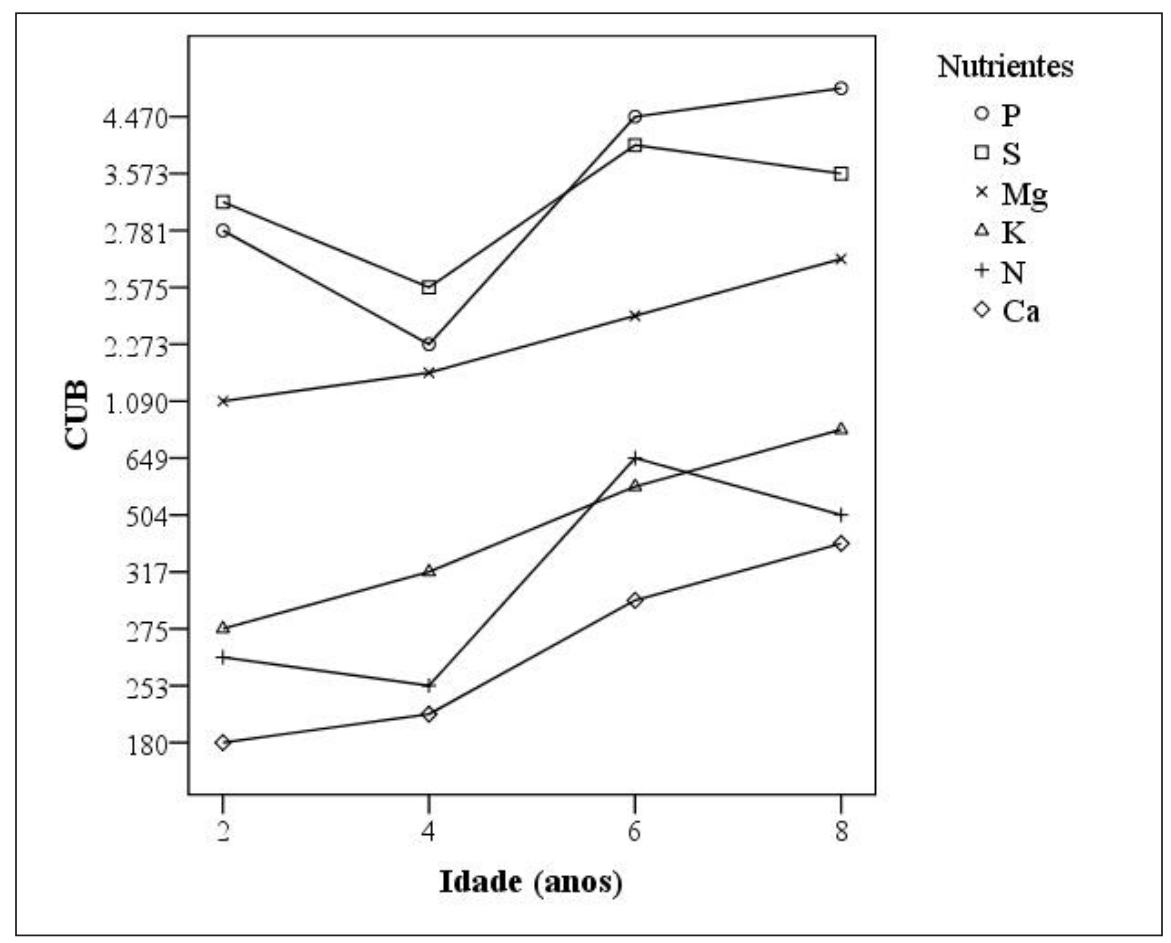

A sustentabilidade nutricional, com base no balanço de nutrientes, pressupõe o equilíbrio entre entradas e saídas de nutrientes no ecossistema florestal (BARROS; COMEFORD, 2002). As entradas de nutrientes podem ocorrer através das deposições atmosféricas (secas e úmidas), intemperismo geológico, fixação biológica de nitrogênio e fertilização, enquanto as saídas incluem a volatilização pela queima ou pela desnitrificação, a lixiviação, a erosão do solo, e em especial, a colheita de biomassa (PRITCHETT, 1990). A entrada de nutrientes via atmosfera é especialmente importante para o nitrogênio e o enxofre e depende de fatores naturais e antrópicos (WARING; SCHLESINGER, 1985), com grande variação de acordo com a localização geográfica, estação do ano e proximidade a grandes centros urbanos, industriais e agrícolas (PRINTCHETT, 1990). De modo geral, nas regiões tropicais, a entrada de nutrientes via mineralização das rochas é tida como pouco expressiva devido ao alto grau de intemperismo desses solos (REIS; BARROS, 1990). As perdas de nutrientes pela lixiviação estão fortemente relacionadas com o tipo de manejo utilizado (REIS; BARROS, 1990). O grau e o período de exposição do solo sem a proteção da vegetação e dos resíduos orgânicos e o uso da queima para eliminação de resíduos de colheita, podem aumentar as perdas por lixiviação e erosão, principalmente, quando coincidirem com períodos com altos índices pluviométricos e condições topográficas desfavoráveis. 
A maior exportação pontual de nutrientes em plantios florestais é a colheita da biomassa (PRITCHETT, 1990; LANDSBERG, 1986). O impacto da colheita florestal, em termos nutricionais, e, por conseguinte, a necessidade de reposição de nutrientes mediante a fertilização, é proporcional a biomassa exportada e o seu teor de nutrientes.

A colheita somente da madeira do tronco é a modalidade mais conservadora de utilização da biomassa e a condição ideal no que se refere à redução do impacto nutricional da colheita da florestal (Figura 5 e Tabela 3).

Na Figura 5 é demonstrado o aumento relativo da exportação de nutrientes e biomassa em decorrência da intensidade de colheita florestal, tomando-se como base o estoque total no Eucalyptus spp. com 8 anos de idade. Comparando-se o tratamento M com o M $+\mathrm{C}+\mathrm{G}+\mathrm{F}$, a exportação de N, P, K, Ca, Mg e S é de 50\% e $91 \%, 37 \%$ e $93 \%, 29 \%$ e $86 \%, 17 \%$ e $91 \%, 23 \%$ e $95 \%, 58 \%$ e $87 \%$, respectivamente, e a biomassa $74 \%$ e $89 \%$. Devido à diferença no conteúdo de nutrientes dos componentes da biomassa, a variação da taxa de exportação entre os diferentes nutrientes e intensidades de colheita, também foi distinta, com destaque para o incremento na exportação de Ca.

\section{Figura 5 - Exportação de biomassa e nutrientes em função da intensidade de colheita florestal: madeira do tronco $(\mathrm{M})$, madeira e casca do tronco $(\mathrm{M}+\mathrm{C})$, madeira e casca do tronco, galhos e folhas $(\mathrm{M}+\mathrm{C}+\mathrm{G}+\mathrm{F})$, em um plantio de Eucalyptus spp., com 8 anos de idade em pequena propriedade rural, Vera Cruz - RS.}

Figure 5 - Biomass and nutrients export according to forest harvesting intensity: wood trunk (M), wood and bark of the trunk $(\mathrm{M}+\mathrm{C})$, wood and bark from the trunk, branches and leaves $(\mathrm{M}+\mathrm{C}+\mathrm{G}+\mathrm{F})$ in a 8 years Eucalyptus spp. stand in a small farm, Vera Cruz, RS state.

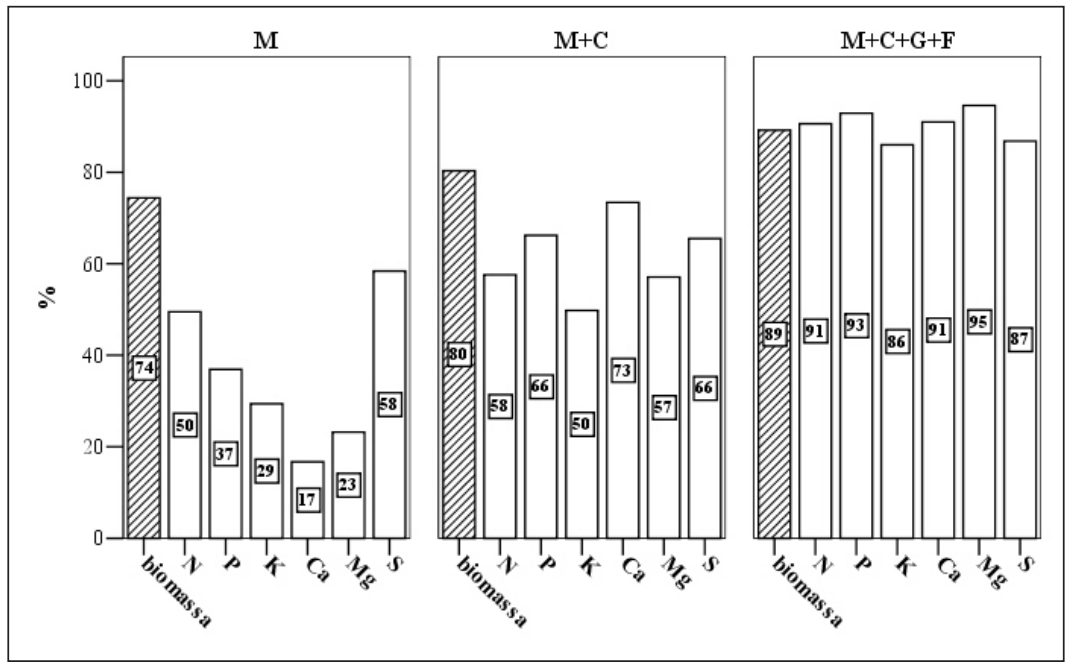

$\mathrm{Na}$ Tabela 3, tendo como base a colheita somente da madeira (M), a remoção da madeira mais a casca do tronco $(\mathrm{M}+\mathrm{C})$ aumentou a exportação de nutrientes entre $12 \%$ para $\mathrm{S}$ e $340 \%$ para $\mathrm{Ca}$, ao passo que a biomassa aumentou somente $8 \%$. Do mesmo modo, mas de forma mais intensa, devido à maior concentração nutricional dos componentes da copa, a colheita total da biomassa acima do solo $(\mathrm{M}+\mathrm{C}+\mathrm{G}$ + F), representou um acréscimo de $20 \%$ na retirada de biomassa, enquanto o incremento na exportação de nutrientes variou de $49 \%$ para S a $445 \%$ para $\mathrm{Ca}$. Em síntese, a colheita de toda biomassa acima do solo, ao contrário de apenas a madeira do tronco, equivale a uma exportação de nutrientes, para $\mathrm{N}, \mathrm{P}, \mathrm{K}, \mathrm{Ca}, \mathrm{Mg}$ e S, respectivamente, de 1,$8 ; 2,5 ; 2,9 ; 5,5 ; 4,1$ e 1,5 vezes superior.

O manejo da biomassa pode ser ainda mais nocivo à sustentabilidade nutricional dos plantios florestais quando envolve a remoção de outros compartimentos como sub-bosque e serapilheira. De modo geral, esses dois compartimentos são complementares, enquanto o sub-bosque é mais importante para nutrientes com alta mobilidade no tecido vegetal, a serapilheira se destaca na retenção de nutrientes imóveis ou de menor mobilidade, $\mathrm{Ca}$ e $\mathrm{Mg}$, respectivamente (Tabela 3). Gonçalves et al. (1997) apud Gonçalves et al. (2004) avaliaram a ciclagem bioquímica de nutrientes em um povoamento de Eucalyptus grandis, entre o oitavo e o nono ano de idade, e verificaram, em média, que $61 \%$ de N, $79 \%$ de $\mathrm{P}, 50 \%$ de $\mathrm{K}$ e $8 \%$ de $\mathrm{Mg}$, 
para folhas decíduas, e $23 \% \mathrm{~N}, 67 \% \mathrm{P}, 8 \% \mathrm{~K}$, para galhos decíduos, foram retranslocados antes da deposição. Nesse estudo, não foi verificada retranslocação de Mg nos galhos e a proporção dos tecidos decíduos, folha e galhos, foi de $60 \%$ e $40 \%$, respectivamente. No caso da serapilheira, também é preciso considerar a fase subsequente à deposição. Segundo Mason (1980), Ca e Mg são ligados mais intimamente no complexo estrutural das moléculas, o que faz com que esses nutrientes sejam lixiviados mais vagarosamente que o K. Em relação ao $\mathrm{N}$, a atividade dos microrganismos que fixam $\mathrm{N}$ da atmosfera pode aumentar a concentração desse nutriente na serapilheira (MASON, 1980). A despeito da pequena biomassa relativa no sub-bosque e serapilheira, em relação à madeira do tronco, $4 \%$ e $7 \%$, respectivamente, ambos retêm um estoque de nutrientes equivalente a $172 \%$ do $\mathrm{Ca}, 138 \%$ do $\mathrm{Mg}, 124 \%$ do $\mathrm{K}, 84 \%$ do $\mathrm{N}, 76 \%$ do $\mathrm{Pe} 49 \%$ do S (Tabela 3 ).

Em termos de rotação, no método mais intensivo de colheita florestal, remoção de toda biomassa acima do solo, incluindo Eucalyptus spp. (M+C + G+F), sub-bosque e serapilheira, a exportação de nutrientes para $\mathrm{N}, \mathrm{P}, \mathrm{K}, \mathrm{Ca}, \mathrm{Mg}$ e $\mathrm{S}$, respectivamente, foi equivalente a um aumento de 1,$7 ; 2,3 ; 3,2 ; 6,2 ; 3,4$ e 1,0, ciclos produtivos, se comparado a retirada apenas da madeira do tronco (M).

Tabela 3 - Estimativa da necessidade de reposição de nutrientes em função da intensidade de colheita da biomassa florestal em um plantio de Eucalyptus spp., com 8 anos de idade em pequena propriedade rural, Vera Cruz - RS.

Table 3 - Estimation of nutrients replace necessity according to forest biomass harvesting intensity in a 8 years Eucalyptus spp. stand in a small farm, Vera Cruz, RS state.

\begin{tabular}{|c|c|c|c|c|c|c|c|c|}
\hline \multirow{2}{*}{\multicolumn{2}{|c|}{ Método de colheita da biomassa }} & \multirow{2}{*}{$\begin{array}{l}\text { Biomassa } \\
\left(\mathbf{M g ~ h a}^{-1}\right)\end{array}$} & $\mathbf{N}$ & $\mathbf{P}$ & $\mathbf{K}$ & $\mathbf{C a}$ & Mg & $\mathbf{S}$ \\
\hline & & & \multicolumn{6}{|c|}{$\mathrm{kg} \mathrm{ha}^{-1}$} \\
\hline \multirow{5}{*}{ Eucalipto } & $\mathrm{M}$ & 173,2 & 228,6 & 15,6 & 91,8 & 107,4 & 20,8 & 38,1 \\
\hline & $\mathrm{M}+\mathrm{C}$ & 187,1 & 266,2 & 28,0 & 155,4 & 472,0 & 51,1 & 42,7 \\
\hline & $(\%)$ & -8 & -16 & -80 & -69 & -340 & -146 & -12 \\
\hline & $\mathrm{M}+\mathrm{C}+\mathrm{G}+\mathrm{F}$ & 207,8 & 418,5 & 39,3 & 268,7 & 585,4 & 84,7 & 56,6 \\
\hline & $(\%)$ & -20 & -83 & -152 & -193 & -445 & -307 & -49 \\
\hline \multicolumn{2}{|l|}{ Sub-bosque } & $6,6(4)$ & $82,0(36)$ & $6,5(42)$ & $67,0(73)$ & $45,4(42)$ & $6,7(32)$ & $10,4(27)$ \\
\hline \multicolumn{2}{|l|}{ Serapilheira } & $12,3(7)$ & $109,1(48)$ & $5,4(35)$ & $46,5(51)$ & $139,6(130)$ & $22,0(106)$ & $8,1(21)$ \\
\hline \multicolumn{2}{|c|}{ Sub-bosque + Serapilheira } & $18,9(11)$ & $191,1(84)$ & $11,9(76)$ & $113,5(124)$ & $185,0(172)$ & $28,7(138)$ & $18,5(49)$ \\
\hline \multicolumn{2}{|c|}{ Biomassa total } & $226,7(31)$ & $609,6(167)$ & $51,2(228)$ & $382,2(316)$ & $770,4(617)$ & $113,4(445)$ & $75,1(97)$ \\
\hline
\end{tabular}

Em que: $\mathrm{M}=$ madeira do tronco; $\mathrm{M}+\mathrm{C}=$ madeira e casca do tronco; $\mathrm{M}+\mathrm{C}+\mathrm{G}+\mathrm{F}=$ madeira e casca, galhos e folhas. Valores entre parênteses referem-se ao incremento relativo na exportação de biomassa e nutrientes em relação à colheita somente da madeira (M). Sub-bosque refere-se à biomassa acima do solo. Biomassa total refere-se ao eucalipto $(\mathrm{M}+\mathrm{C}+\mathrm{G}+\mathrm{F})$, sub-bosque (acima do solo) e serapilheira.

A exportação de nutrientes pela colheita da biomassa pode ser compensada por outros fluxos naturais pertencentes à ciclagem de nutrientes ou mediante adição de fertilizantes e outros tipos de insumos (cinzas, resíduos de colheita, compostos orgânicos, entre outros). No entanto, a reposição por meio da adubação, além das implicações econômicas e ecológicas do seu uso, dificilmente é feita na mesma ordem quantitativa e qualitativa da exportação pela colheita florestal; geralmente se restringindo à formulação NPK, o que pode comprometer a capacidade produtiva dos sítios florestais.

Uma adequada intensidade de colheita da biomassa deve ser associada ao correto manejo do solo e dos resíduos pós-colheita. Os componentes da biomassa de eucalipto que não são removidos pela colheita, além da serapilheira e vegetação de sub-bosque, devem ficar dispostos sobre o solo, de modo que protejam a superfície do solo do impacto da chuva e do escorrimento superficial, reduzam a infestação de plantas invasoras e estimulam a atividade biológica de organismos do solo (WARING; SCHLESINGER, 1985; GONÇALVES et al., 2004).

A prática do fogo para limpeza de áreas de plantio (redução do volume de resíduos culturais) é 
totalmente desaconselhável pelos reflexos negativos na atividade biológica do solo, perdas de nutrientes no processo de combustão da biomassa, exposição da superfície do solo a extremos térmico e de umidade, aumento da erosão hídrica e eólica e lixiviação de nutrientes. O processo de combustão da biomassa libera grandes quantidades de nutrientes que ficam depositados na superfície do solo na forma de cinzas, e são facilmente perdidos por lixiviação ou erosão hídrica ou eólica. Maluf (1991) apud Gonçalves et al. (2004), em Eucalyptus camaldulensis na região dos cerrados, verificou que a queima dos resíduos florestais resultou em perda de $88 \%$ do N, 33\% do P, 30\% do K, $47 \%$ do Ca e $43 \%$ do $\mathrm{Mg}$ contidos nos resíduos.

O grande volume de resíduos de colheita, que em replantios comerciais mecanizados pode dificultar o uso de alguns implementos (GONÇALVES et al., 2004), em nível de pequena propriedade rural, na qual o nível de mecanização é menos intenso no plantio e replantio de povoamentos florestais, é possível utilizar intensamente os benefícios advindos do cultivo mínimo do solo, principalmente no que diz respeito ao manejo dos resíduos de colheita florestal.

\section{Conclusões}

Os fundamentos da ciclagem de nutrientes devem ser aplicados ao manejo da biomassa para manter a fertilidade do solo e diminuir a necessidade de adubação. Nesse sentido, o sub-bosque e a serapilheira são importantes compartimentos para a manutenção dos nutrientes no sistema.

A ciclagem interna de nutrientes aumenta a eficiência de utilização dos nutrientes (CUB) ao longo da idade do povoamento, reduzindo a exportação relativa de nutrientes pela colheita florestal. $\mathrm{O}$ aumento da biomassa relativa em função da idade contribui para um maior rendimento de madeira nos povoamentos após os 6 anos de idade.

A restrição da exportação de biomassa somente à madeira do tronco, mantendo casca do tronco, raiz e os demais componentes da copa como resíduo sobre o solo, é a medida mais importante para a redução do impacto nutricional da colheita florestal.

A observância à idade de colheita florestal e à intensidade de remoção da biomassa associadas ao manejo correto dos resíduos pós-colheita, são medidas efetivas à sustentabilidade nutricional de plantios de eucalipto.

\section{Agradecimentos}

Ao Sindicato da Indústria do Fumo - SINDIFUMO e à Associação dos Fumicultores do Brasil AFUBRA, pela viabilização econômica deste estudo. Aos proprietários rurais: José Hildor Hoff, Norberto Petry, Lauri Zibel e Ari Müller, que permitiram o levantamento dos dados em suas florestas. À Prefeitura municipal da cidade de Vera Cruz, pela cessão de equipamento.

\section{Referências}

ASSIS, R. L. et al. Produção de biomassa de Eucalyptus urophylla S.T. Blake sob diferentes espaçamentos da região de cerrado de Minas Gerais. Revista Árvore, Viçosa, MG, v. 23, n. 2, p. 151-156, abr./jun. 1999.

BARROS, N. F. et al. Classificação nutricional de sítios florestais - descrição de uma metodologia. Revista Árvore, Viçosa, MG, v. 10, n. 1, p. 112-120, jan. 1986.

BARROS, N. F.; COMEFORD, N. B. Sustentabilidade da produção de florestas plantadas na região tropical. In: ALVAREZ, V. et al. (Ed.). Tópicos em ciência do solo. Viçosa, MG: Sociedade Brasileira de Ciência do Solo; Folha de Viçosa, 2002. v. 2. p. 487-592.

BELLOTE, A. F. J.; SILVA, H. D. Sampling techniques and nutritional evaluations in eucalypt plantations. In: GONÇALVES, J. L. M.; BENEDETTI, V. (Ed.). Forest nutrition and fertilization. 2nd ed. Translation: Ken McNabb; Piracicaba: IPEF, 2004. p. 113-139.

BINKLEY, D. Forest nutrition management. New York: John Wiley \& Sons, 1986. 290 p.

BURGER, L. M.; RICHTER, H. G. Anatomia da Madeira. São Paulo: Nobel, 1991. 154 p. 
COSTA, L. M. Manejo de solos em áreas florestais. In: BARROS, N. F.; NOVAIS, R. F. (Ed.) Relação solo eucalipto. Viçosa, MG: Folha de Viçosa, 1990. p. 237-302.

EPSTEIN, E.; BLOOM, A. J. Nutrição mineral de plantas. Londrina: Planta, 2006. 403 p.

GONÇALVES, J. L. M. et al. An evaluation of minimum and intensive soil preparation regarding fertility and tree nutrition. In: GONÇALVES, J. L. M.; BENEDETTI, V. (Ed.). Forest nutrition and fertilization. 2nd ed. Translation: Ken McNabb; Piracicaba: IPEF, 2004. p. 13-64.

GUREVITCH, J.; SCHEINER, S. M.; FOX, G. A. Ecologia Vegetal. 2. ed. Porto Alegre: Artmed, 2009. $592 \mathrm{p}$.

INDÚSTRIA BRASILEIRA DE ÁRVORES. Indicadores de desempenho do setor nacional de árvores plantadas: ano base 2015. Brasília: IBA, 2016. 98 p.

LADEIRA, B. C. et al. Produção de biomassa de eucalipto sob três espaçamentos em uma seqüência de idade. Revista Árvore, Viçosa, MG, v. 25, n. 1, p. 69-78, jan./mar. 2001.

LAL, R.; KIMBLE, J.; FOLLETT, R. F. Pedospheric processes and the carbon cycle. In: LAL, R. et al. (Ed.). Soil processes and the carbon cycle. [S.1.]: CRC Press LLC, 1998. p. 1-8.

LANDSBERG, J. J. Physiological ecology of forest production. London: Academic Press, 1986. 198 p.

LEITE, F. P. et al. Crescimento de Eucalyptus grandis em diferentes densidades populacionais. Revista Árvore, Viçosa, MG, v. 21, n. 3, p. 313-321, jul./set. 1997.

MASON, C. F. Decomposição. São Paulo: EDU, 1980. 63 p.

MIYAZAWA, M. et al. Análises químicas de tecido vegetal. In: SILVA, F. C. (Org.). Manual de análises químicas de solos, plantas e fertilizantes. Brasília: EMBRAPA Comunicação para Transferência de Tecnologia, 1999. p. 171-224.

MORENO, J. A. Clima do Rio Grande do Sul. Porto Alegre: Secretaria da Agricultura, 1961. 31 p.

MARSCHNER, H. Mineral nutrition of higher plants. 2. ed. London: Academic Press, 1995. 889 p.

PALLARDY, S. Physiology of woody plants. San Diego: Academic Press, 2008. 454 p.

PEREIRA, A. R. et al. Concentração e distribuição de nutrientes em Eucalyptus grandis em função da idade, cultivado na região do cerrado. Brasil Florestal, Brasília, n. 59, p. 27-37, jul./set. 1984.

POGGIANI, F.; SCHUMACHER, M. V. Nutrient cycling in native forests. In: GONÇALVES, J. L. M.; BENEDETTI, V. (Ed.). Forest nutrition and fertilization. 2nd ed. Translation: Ken McNabb; Piracicaba: IPEF, 2004. p. 287-305.

PRITCHETT, W. L. Suelos forestales: propriedade, conservación y mejoramento. México: Limusa Noriega, 1990. 634 p.

REIS, M. G. F.; BARROS, N. F. Ciclagem de nutrientes em plantios de eucalipto. In: BARROS, N. F.; NOVAIS, R. F. (Ed.). Relação solo eucalipto. Viçosa, MG: Folha de Viçosa, 1990. p. 265-302.

TROEH, F. R.; THOMPSON, L. M. Solos e fertilidade do solo. 6. ed. São Paulo: Andrei, 2007. 718 p.

VIEIRA, E. F. Rio Grande do Sul: geografia, física e vegetação. Porto Alegre: Sagras, 1984. 184 p.

WARING, R. H.; SCHLESINGER, W. H. Forest ecosystems: concepts and management. San Diego: Academic Press, 1985. 340 p. 